\title{
Prevention of chronic rejection after lung transplantation
}

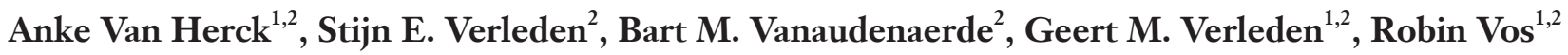 \\ ${ }^{1}$ Department of Respiratory Diseases, University Hospitals Leuven, Leuven, Belgium; ${ }^{2}$ Department of Chronic Diseases, Metabolism \& Ageing \\ (CHROMETA), Division of Respiratory Diseases, KU Leuven, Leuven, Belgium \\ Contributions: (I) Conception and design: A Van Herck, R Vos; (II) Administrative support: None; (III) Provision of study materials or patients: None; \\ (IV) Collection and assembly of data: A Van Herck, R Vos; (V) Data analysis and interpretation: A Van Herck, R Vos; (VI) Manuscript writing: All \\ authors; (VII) Final approval of manuscript: All authors. \\ Correspondence to: Prof. Dr. Robin Vos. Department of Respiratory Diseases, University Hospitals Leuven, Lung Transplantation Unit, KU Leuven, \\ Herestraat 49, B-3000 Leuven, Belgium. Email: robin.vos@uzleuven.be.
}

\begin{abstract}
Long-term survival after lung transplantation (LTx) is limited by chronic rejection (CR). Therapeutic strategies for CR have been largely unsuccessful, making prevention of CR an important and challenging therapeutic approach. In the current review, we will discuss current clinical evidence regarding prevention of CR after LTx.
\end{abstract}

Keywords: Chronic lung allograft dysfunction; lung transplantation (LTx); prevention; treatment

Submitted Sep 01, 2017. Accepted for publication Nov 07, 2017.

doi: $10.21037 /$ jtd.2017.11.85

View this article at: http://dx.doi.org/10.21037/jtd.2017.11.85

\section{Introduction}

During the last decades, short-term outcomes after lung transplantation (LTx) have improved due to advances in immunosuppressive regimens and better peri- and postoperative care. Despite significant improvement of early survival, however, long-term survival remains limited, with a median 5 -year survival of approximately $54 \%$ and a median 10 -year survival of $32 \%$ (1). Long-term survival after LTx is mainly hampered by the development of chronic rejection (CR) $(1,2)$. CR in this review is defined as a sustained decrease in pulmonary function (forced expiratory volume in one second, $\mathrm{FEV}_{1}$ ) of $\geq 20 \%$ from the average of the patient's two best post-transplant values ('baseline'), in the absence of other identifiable causes. CR affects $45 \%$ of all LTx recipients within 5 years following LTx, which is the highest prevalence in solid-organ transplantations, and accounts for the majority of late post-transplant mortality $(3,4)$. There are at least two different clinical manifestations of CR: bronchiolitis obliterans syndrome (BOS) - an obstructive phenotypeand restrictive allograft syndrome (RAS) or restrictive CRa restrictive phenotype. Median survival after BOS diagnosis is 3 to 5 years, whereas median survival after RAS diagnosis is limited to 0.5 to 1.5 years $(5,6)$.
Since long-term survival after LTx is hampered by the development of CR and therapeutic strategies have been largely unsuccessful, prevention of CR is an important and challenging therapeutic approach (7-11). Current prophylactic practices mostly include an immunosuppressive induction therapy, a maintenance therapy with conventional triple drug immunosuppression (mostly methylprednisolone, a calcineurin inhibitor and a cytostatic agent) and prevention of risk factors for CR, including conventional infectious prophylaxis.

Despite the importance of preventive strategies, randomized trials are scarce. In the current paper, we will review clinical evidence aimed at prevention of CR after LTx (schematically summarized in Figure 1). Data derived from in vitro or animal studies are considered to be too premature and outside the scope of the current review.

\section{Immunosuppression}

\section{Induction therapy}

Induction therapy is an intense immunosuppressive therapy administered at the time of LTx with the aim of reducing early acute rejection (AR). AR has been shown to be the 


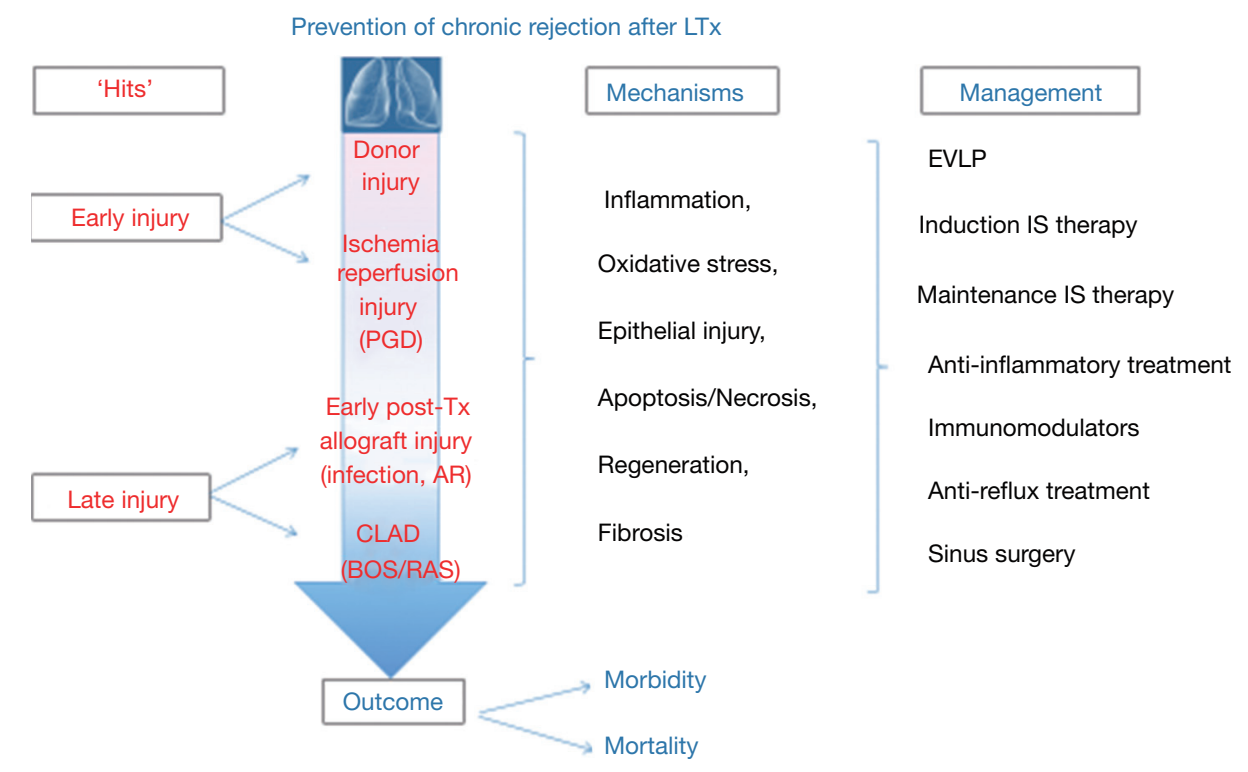

Figure 1 Schematic presentation of the possible strategies for prevention of CR after LTx. PGD, primary graft dysfunction; AR, acute rejection; CLAD, chronic lung allograft dysfunction; BOS, bronchiolitis obliterans syndrome; RAS, restrictive allograft syndrome; EVLP, ex vivo lung perfusion; IS, immunosuppression; LTx, lung transplantation.

leading risk factor for CR. Induction therapy may reduce the incidence of early AR and hence, the subsequent development of CR (12). Also, induction therapy provides a longer timeframe to achieve therapeutic calcineurin inhibitor levels in the early post-operative period, allowing the kidneys to recover after surgery before experiencing toxic effects of CNI (9). Two categories of induction therapy are widely used: monoclonal or polyclonal lymphocytedepleting agents and interleukin-2 receptor antagonists (IL2RA). According to the International Society for Heart and Lung Transplantation (ISHLT) registry, approximately $70 \%$ of LTx patients nowadays receive an induction treatment, most of them with IL2RA (1).

\section{IL2RAs: daclizumab, basiliximab}

Daclizumab and basiliximab are monoclonal agents directed against the interleukin-2 receptor of T-cells. Daclizumab and basiliximab saturate the alpha-subunit of this receptor, thereby preventing para-/autocrine activation and proliferation of T-cells by interleukin-2 $(9,13)$. Evidence concerning these induction agents is conflicting. Multiple small retrospective and prospective trials demonstrated a decrease in AR episodes and prolonged CR-free and overall survival with daclizumab induction in comparison to antithymocyte globulin (ATG) induction or conventional immunosuppression with corticosteroids, a calcineurin inhibitor and a cytostatic agent (14-16). In contrast however, other small retrospective trials demonstrated an increase in episodes of $\mathrm{AR}$ and $\mathrm{CR}$ incidence with daclizumab or basiliximab compared with ATG $(17,18)$. In addition, a prospective trial comparing OKT3, ATG and daclizumab induction found no difference in episodes of AR, CR-free or overall survival between these three groups (19).

\section{Lymphocyte-depleting agents: ATG, OKT3, alemtuzumab}

ATG is a polyclonal lymphocyte-depleting agent that acts through complement mediated and antibody-related cell lysis and through opsonization and phagocytosis by macrophages $(9,13)$. ATG was demonstrated in a RCT to be superior to conventional immunosuppression with corticosteroids, a calcineurin inhibitor and a cytostatic agent in preventing early AR (20). However, there were no differences in late post-transplant outcome, such as CR and survival (21).

OKT3 is a monoclonal lymphocyte-depleting agent that acts through binding of the T-cell receptor CD3 complex $(9,13)$. Two prospective trials could not demonstrate a difference in AR, CR-free and overall survival after OKT3 induction compared to induction with $\operatorname{ATG}(19,22)$. Moreover, OKT3 was associated with more adverse effects, in particular with more bacterial infections (19). 
Alemtuzumab is a monoclonal lymphocyte-depleting agent that acts through binding of CD52 on the cell surface of $\mathrm{B}$ and $\mathrm{T}$ cells, monocytes, macrophages and natural killer cells $(9,13)$. In a study of Wehman et al. alemtuzumab induction with reduced immunosuppression showed a comparable rate of AR and overall survival in comparison to conventional immunosuppression with corticosteroids, a calcineurin inhibitor and a cytostatic agent (23). In addition, Shyu et al. could demonstrate an improved freedom from AR and lymphocytic bronchiolitis and a prolonged CR-free survival in LTx patients induced with alemtuzumab in comparison to LTx patients induced with ATG, daclizumab or conventional immunosuppression. Overall survival after induction with alemtuzumab was comparable to ATG induction and better than induction with daclizumab or conventional immunosuppression (24). However, alemtuzumab was only introduced the last decade, and evidence from randomized controlled trials is lacking.

A recent meta-analysis could not demonstrate any statistically significant differences between the use of T-cell antibody induction compared with no induction, or different types of T-cell antibodies discussed above regarding AR, CR-free and overall survival (25). Nevertheless, this metaanalysis was limited to the size and nature of the limited number of available studies.

\section{Maintenance therapy}

LTx patients usually receive a triple drug immunosuppression maintenance therapy consisting of corticosteroids, a cytostatic agent and a calcineurin inhibitor. Such a regimen provides more effective immunosuppression and minimizes side effects of drugs utilized by allowing lower target levels $(1,9)$. According to the ISHLT, the most used combination therapy at 1 and 5 years post-LTx consists of tacrolimusmycophenolate mofetil (MMF)-corticosteroids (1).

\section{Corticosteroids}

Corticosteroids attenuate inflammation by inducing neutrophil leukocytosis and a transient reduction in circulating eosinophils, monocytes, and lymphocytes. In contrast, antibody production is preserved, since B-cells are less affected by corticosteroids (26). Systemic corticosteroid use is widely considered an important component of immunosuppressive regimens after solid organ transplantation, despite numerous and frequent side-effects $(1,27)$. Despite their widespread use in most immunosuppressive regimens, no randomized trials on prevention of CR after LTx are available. Whether systemic corticosteroids can be safely stopped after LTx, without increasing the risk for subsequent development of CR, remains also unknown.

Airway inflammation is known to be suppressed by inhaled corticosteroids in other chronic inflammatory lung diseases such as asthma and chronic obstructive pulmonary disease (COPD) $(28,29)$. Inhaled corticosteroids have been shown to reduce the total cell numbers in bronchoalveolar (BAL) fluid of LTx patients in a randomized placebocontrolled trial (30). In contrast with these findings, neither cell differentials, nor lung function were altered after adding 3 months inhaled corticosteroids to a systemic therapy of corticosteroids in LTx (31). These findings suggest that inhaled corticosteroids are ineffective for the prevention of CR after LTx, although more research is needed regarding adequate local delivery and timing of this therapy.

\section{Cytostatic agents: azathioprine (AZA) and MMF}

AZA and MMF are antimetabolites or antiproliferative agents which inhibit the purine and/or pyrimidine synthesis and thus block the de novo pathway of nucleotide synthesis in cells. In addition to this de novo pathway, a salvage pathway also provides nucleotide synthesis in most cells. As lymphocytes lack a salvage pathway, AZA and MMF specifically exert their antiproliferative effect on these cells $(26,27)$.

MMF has proven to decrease the incidence of AR and to prolong overall and CR-free survival in renal and heart transplant recipients compared to AZA $(32,33)$. LTx recipients treated with $M M F$ also showed less episodes of $\mathrm{AR}$ and a slower decline in $\mathrm{FEV}_{1}$ in comparison to AZA in non-randomized trials (34-36). Moreover, MMF significantly reduced graft loss due to CR in comparison to AZA in LTx (37). In contrast to these findings, two randomized trials could not demonstrate a difference in AR rates, CR-free and overall survival between MMF or AZA maintenance treatment $(38,39)$. Therefore, despite the increasing use of MMF, there is limited evidence of superiority of MMF over AZA in LTx (9).

\section{Calcineurin inhibitors: cyclosporine, tacrolimus}

Cyclosporine forms a complex with cyclophilin, while tacrolimus binds to FK-binding protein or immunophilin in the cell cytoplasm of T-cells. These complexes both inhibit calcineurin from translocating to the nucleus, resulting in a lack of IL-2 mRNA transcription, which is needed for activation and proliferation of $\mathrm{T}$ lymphocytes. The 
limited amount of calcineurin in immune cells compared to other cell types, as well as the fact that calcineurin is critical for T-cell activation, accounts for the sensitivity of T-lymphocytes to cyclosporine and tacrolimus $(9,40)$.

Tacrolimus has demonstrated superiority over cyclosporine in a limited number of randomized studies regarding CR incidence, CR-free survival, lymphocytic bronchiolitis and arterial hypertension (41-45), without an effect on AR or survival $(41,43,45)$. On the other hand, tacrolimus may be associated with a higher incidence of post-transplant diabetes $(44,46)$. Single center placebocontrolled trials could demonstrate an extended CR-free and overall survival when adding inhaled cyclosporine to the maintenance immunosuppression therapy after LTx (47-49). However, a subsequent multi-centre randomized controlled trial failed to demonstrate a difference in CR-free survival and overall survival (50).

\section{Mammalian target of rapamycin (mTOR) inhibitors: everolimus, sirolimus}

Everolimus and sirolimus block mTOR and inhibit growth factor-stimulated proliferation of lymphocytes and mesenchymal cells. According to the ISHLT registry, the use of mTOR inhibitors increases from approximately $8 \%$ 1 year after transplantation versus approximately $16 \%$ 5 years after $\operatorname{LTx}(1,9)$.

Two multicenter randomized trials could not show a difference in CR incidence, CR-free and overall survival between everolimus and AZA, or everolimus and de novo enteric-coated mycophenolate sodium as part of the triple immunosuppression regimen after LTx. Moreover, everolimus was associated with more severe adverse events (39,51). Similarly, Bhorade et al. could not demonstrate superiority of sirolimus in comparison to AZA regarding AR rate and incidence of CR (52). Sacher et al. on the other hand showed a lower incidence of CR and improved overall survival in patients treated with sirolimus compared to patients treated with MMF (53). However, sirolimus was also associated with significant adverse effects including venous thromboembolism and impaired bronchial anastomosis healing (52-54).

However, therapy with a mTOR inhibitor may provide an advantage in specific situations. Long-term calcineurin inhibitor use often leads to nephrotoxicity. Adding an mTOR to minimize calcineurin inhibitor exposure, may improve renal function without significant change in $A R$ and $\mathrm{FEV}_{1}(55,56)$. Additionally, mTOR inhibitors seem to be associated with a decreased incidence of cytomegalovirus
(CMV) infections in solid-organ transplant patients $(52,57)$.

\section{Immunomodulation}

\section{Neomacrolide antibiotics}

Azithromycin and clarithromycin are neomacrolide antibiotics with a macrolactam ring. Both antibiotics are derived from erythromycin, an antibiotic with a macrocyclic lactone ring, which has been isolated from Streptomyces species (58).

\section{Azithromycin}

Azithromycin has both antimicrobial and immunomodulatory properties (59). Antimicrobial properties against grampositive (e.g., S. pneumoniae and S. aureus), gram-negative (e.g., H. influenzae and M. catarrbalis) and atypical pathogens (e.g., Chlamydia, Mycoplasma, Listeria, Pneumocystis and Legionella spp.) are achieved by binding of the 50S ribosome subunit of bacteria, lowering protein synthesis. Antimicrobial activity against $P$. Aeruginosa is accomplished by reducing quorum sensing-dependent virulence factors, reducing alginate and biofilm formation, reducing protein synthesis and interaction with outer cellular membrane proteins (58). Immunomodulatory properties are achieved by influencing multiple cytokines and chemokines, and in this way lowering airway inflammation and airway remodeling. Exact cellular mechanisms are beyond the scope of this review and are summarized elsewhere (59).

Several studies have demonstrated azithromycin to improve $\mathrm{FEV}_{1}$ by an average of $15 \%$ in $30-83 \%$ and overall survival in approximately $35-40 \%$ of LTx recipients diagnosed with CR (60-70). A randomized controlled trial of Corris et al. in established BOS demonstrated a mean difference in $\mathrm{FEV}_{1}$ of $0.3 \mathrm{~L}$ in favor of azithromycin versus placebo (70). Especially patients with increased BAL lavage neutrophilia ( $>15-20 \%)$ are more successfully treated (67). In some of these azithromycin-treated patients, $\mathrm{FEV}_{1}$ no longer meets the spirometric criteria for CR, which condition is denominated neutrophilic reversible allograft dysfunction (NRAD) or azithromycin responsive allograft dysfunction (ARAD) $(67,71)$. NRAD/ARAD is typically characterized by neutrophilic airway inflammation, coarse crackles and increased sputum production and bronchiectasis, airway wall thickening, mucous plugging and centrilobular nodules on chest CT. Histology initially shows an inflammatory process, but may end up in fibrosis. Prognosis of NRAD/ARAD is good (71). Therefore, 
current management guidelines recommend a trial of azithromycin for a least 3 months once CR is suspected (72).

Importantly, azithromycin is also effective as preventive therapy for CR. A randomized placebo-controlled trial of azithromycin demonstrated that prophylactic azithromycin reduces CR prevalence and improves CR-free survival. In this trial, CR prevalence is reduced with $32 \%$ after 2 years and with $23 \%$ after 7 years $(73,74)$. Overall survival between the two groups is similar, most likely due to initiation of open-label azithromycin treatment in patients with established CR. Patients treated with azithromycin also demonstrated higher pulmonary function $\left(\mathrm{FEV}_{1}\right)$, better functional exercise capacity, lower airway neutrophilia and lower systemic C-reactive protein levels over time compared to those receiving placebo $(73,74)$.

In patients with established NRAD/ARAD, multiple cytokines/chemokines and proteins are upregulated. One study shows that MMP-gelatinase is increased in BAL fluid of these patients. After 3 to 6 months of treatment with azithromycin, MMP-gelatinase was decreased compared with patients not treated with azithromycin, but still increased compared to stable patients. These findings suggest an ongoing matrix remodeling process, despite treatment with azithromycin, and thus possibly a higher risk to later development of CR. These findings suggest that a preventive approach with azithromycin may be preferred to a therapeutic approach (71).

Possible adverse events of azithromycin include nausea, vomiting, diarrhea or abdominal pain due to stimulation of gut motility. Cardiovascular events, particularly arrhythmias, mainly in case of concomitant use of other QT-prolonging medicines or underlying structural heart disease should be taken into account (75). However, the absolute risk of fatal cardiac arrhythmia is low and in fact comparable to that of alternative antibiotics (76). Azithromycin may be considered the safest of all macrolides since serum levels in healthy volunteers are $>3,000$ times lower than drug concentrations required for cardiomyocyte potassium channel (hERG/IKr)blockade, action potential prolongation and QTc prolongation (22-24). Caution is nevertheless required for toxic accumulation of azithromycin in patients with impaired hepatic function, in case of concomitant use of other QT-prolonging drugs, or underlying structural heart disease. Another concern is the potential for emergence of bacterial resistance with long-term use of azithromycin, although this has not been show yet in microbiome studies in patients long-term treated with azithromycin $(77,78)$.

\section{Clarithromycin}

Long-term treatment with clarithromycin in lung transplant recipients with established CR results in an improved $\mathrm{FEV}_{1}$ in approximately one-third of patients in comparison to placebo. These results are comparable to long-term azithromycin therapy (79). On the other hand, Dhillon et al. could not demonstrate beneficial effects when using clarithromycin to prevent CR (80). The reason for this discrepancy with azithromycin is unclear. However, in contrast to clarithromycin, azithromycin does not affect calcineurin levels, making azithromycin the neomacrolide of preference for both prevention and treatment of CR post$\operatorname{LTx}(81,82)$.

\section{Montelukast (MLK)}

MLK is a leukotriene-receptor antagonist (LTRA) with anti-inflammatory properties, which has particularly an effect on eosinophilic airway inflammation (83). A single center study in patients with pulmonary graft versus host syndrome disease after bone marrow transplantation, a disease showing similarities to CR after LTx, demonstrated an improvement in pulmonary function after treatment with MLK (84). Consecutively, a retrospective pilot study with MLK in patients with established CR, unresponsive to azithromycin, showed attenuation of the $\mathrm{FEV}_{1}$ decline from $112 \pm 26$ to $13 \pm 13 \mathrm{~mL} /$ month after 6 months treatment with MLK. In the control group, there was no significant change in the rate of $\mathrm{FEV}_{1}$ decline (85). Unpublished data of our group demonstrate that in particular patients with BOS stage 1 unresponsive to azithromycin therapy may benefit from MLK treatment (Ruttens et al., in revision).

\section{Statins}

Statins inhibit 3-hydroxy-3-methylglutaryl-coenzyme A reductase and by doing so reduce cholesterol. Besides this primary mechanism of action, statins also influence endothelial function and have immunomodulatory effects that are unrelated to their cholesterol-lowering function $(86,87)$. Johnson et al. demonstrated that pulmonary function is better in LTx recipients post-operatively receiving statins in comparison to non-treated patients. Moreover, less and less severe episodes of $\mathrm{AR}$ and a better 6-year survival (91\% versus 54\%) were noted. Also a trend for a lower CR prevalence ( $0 \%$ versus $37 \%$ ) was seen in statin-treated patients in comparison to placebo (88). Another study demonstrated an association between post- 
operative administration of statins and better CR-free and overall survival (89). These studies point to beneficial effect of preventive treatment with statins after LTx, yet the exact dose and duration of therapy is currently unknown. Also, he exact mechanism is unknown, but some of the beneficial effects can possibly be explained by reduction in primary graft dysfunction (PGD) grade 2 and grade 3 in patients taking statins prior to LTx (90). Since PGD is associated with an increased risk for CR one could argue that statins decrease CR development by reducing PGD $(87,91)$. However, Johnson et al. demonstrated a trend towards a lower CR-free survival, despite that statins were started only 1 year after LTx (88). This suggests that statins, next to reducing PGD, may exert other effects which influence CR-free and overall survival.

\section{Vitamin D}

Vitamin D is a fat-soluble vitamin obtained by diet or through the skin that requires conversion in the liver or the kidneys to become metabolically active. Vitamin D was shown to have beneficial effects in asthma, COPD, and tuberculosis, demonstrating improved pulmonary function, reduced airway remodeling and a decrease in exacerbations $(92,93)$. Since vitamin D has immunomodulatory functions, there may also be a possible beneficial effect of a preventive treatment with high doses of vitamin $\mathrm{D}$ after LTx (92). However, a randomized controlled trial could not demonstrate an improvement in CR prevalence and CR-free survival with vitamin D. Other secondary endpoints, including AR, were not different as well (94).

\section{Extracorporeal photopheresis (ECP)}

Intensified immunosuppression is obtained with ECP, in which leucocytes in the blood are isolated, incubated with 8-methoxypsoralen and subsequently exposed to ultraviolet-A light before re-entering the patient. This induces lymphocyte apoptosis, which likely causes an immunomodulatory effect via increase and activation of regulatory T-cell activation and thus can be considered as a type of T-cell vaccination (95).

Several studies demonstrated stabilization or improvement of $\mathrm{FEV}_{1}$ and a better overall survival after addition of ECP to standard immunosuppressive therapy in LTx recipients diagnosed with CR (95-99). In particular LTx patients diagnosed with BOS with elevated BAL neutrophilia and slow decline in $\mathrm{FEV}_{1}(<100 \mathrm{~mL} / \mathrm{month})$ seem to benefit from ECP (95). LTx patients with recurrent episodes of AR were also found to have an overall superior survival after ECP treatment, making ECP possibly a promising treatment to prevent CR (100). Currently, early post-LTx ECP as pre-emptive strategy is being investigated (abstract of unpublished data: Jaksch et al. J Heart Lung Transplant 2014;32:803).

\section{Prevention of risk factors}

\section{Ischemia-reperfusion injury}

PGD due to ischemia-reperfusion injury, remains an important short and long-term complication after LTx (101). PGD occurs within the first 72 hours after LTx and is characterized by pulmonary edema with diffuse alveolar damage and infiltrates on chest CT. PGD clinically manifests itself as hypoxemia and is associated with CR-free and overall survival (102-105).

New preservation strategies of donor lungs revealed possibilities for attenuating PGD and increasing CR-free and overall survival. Improved preservation solutions, such as low potassium dextran and Celsior, have been associated with improved outcome $(106,107)$. However, clinically ex vivo lung perfusion (EVLP) shows the greatest potential as ex vivo assessment of the lungs allows interventions to potentially improve lung quality by reducing inflammation and early immune activation. A leukocyte filter can decrease the load of inflammatory cells within the graft, while treatment with mesenchymal stem cells lead to a decrease in pulmonary inflammation $(108,109)$. Tikkanen et al. could demonstrate an increased CR-free and overall survival when using EVLP in contrast to cold preservation of donor lungs, particularly in brain death donors (110). Long-term clinical results, including pulmonary function and CR, from a prospective, randomised, multi-center trial (INSPIRE) to compare lung allograft preservation by EVLP with standard cold storage are expected in 2017.

\section{$A R$}

Acute (perivascular) rejection (AR) is diagnosed based on the presence of perivascular and interstitial mononuclear cell infiltrates on transbronchial biopsy. The severity of AR is defined by the distribution and extension of these infiltrates and ranges from A0 (no rejection) to A4 (severe) (111). Episodes of minimal (A1), but especially mild and severe AR $(A \geq 2)$ are associated with higher incidence of CR 
(112-115). The significance and treatment of minimal AR (grade A1) remains controversial. However, when grade A1 rejection is diagnosed, treatment with a short course of systemic steroids is recommended since the possible benefits of this therapy exceed the risks $(12,72,112,116)$. Case-control studies with augmented immunosuppression in patients with non-minimal AR (grade $\geq \mathrm{A} 1$ ) after LTx are not available, since it is widely accepted that augmenting immunosuppression and a short course of systemic steroids is the appropriate treatment of non-minimal AR $(1,72)$. However, indirect evidence suggests that augmented immunosuppression and a short course of systemic steroids may decrease the risk of subsequent $\mathrm{CR}$ in patients with non-minimal AR $(113,117)$.

\section{Lymphocytic bronchiolitis}

Lymphocytic bronchiolitis represents acute airway inflammation and is characterized by a lymphocytic infiltration in the submucosa of bronchioles on histopathology with grades range from B0 (no rejection) to B2R (high grade rejection) (111). Lymphocytic bronchiolitis is an established risk factor for CR $(88,90,91,94,95)$. Azithromycin decreases IL-17 driven neutrophilia in lymphocytic bronchiolitis and may as such reduces CR incidence (118). A short course of systemic steroids is advised as well, although convincing evidence is lacking (72). One study demonstrated a beneficial effect of inhaled steroids in LB, but evidence for preventive treatment with inhaled steroids is lacking (119).

\section{Anti-buman leucocyte antigen (HLA) antibodies}

Donor specific antibodies (DSA), mostly anti-HLA antibodies, but also non-HLA antibodies, originate when the lung allograft is recognized by the recipient's immune system as non-self despite immunosuppressive treatment (120-126).

HLA antibodies have been associated with persistent, recurrent, high-grade AR and to lymphocytic bronchiolitis $(125,126)$. Some $10 \%$ to $50 \%$ of LTx patients may develop DSA (mostly DQ) (121). Detection of de novo HLA DSA is linked with severity of CR and overall survival (121-124). Non-HLA antibodies to self-antigens (for example collagen $\mathrm{V}, \mathrm{K}-\alpha 1$ tubulin) are also known to be associated with an increased risk of CR and worse outcome after LTx (120-124). These findings suggest that (non-)HLA antibodies may have a pathogenic role in the development of $\mathrm{CR}$ and that clearing or preventing formation of these antibodies might reduce CR-prevalence.

In a study of Snyder et al., an aggressive desensitization protocol with plasmapheresis, solumedrol, bortezomib and rituximab did not decrease HLA antibodies in sensitized LTx recipients, nor improve survival (127). In a prospective observational study of Hachem et al., patients were started on preemptive antibody-directed therapy with rituximab and monthly intravenous immunoglobulins (IVIG) or monthly IVIG alone once they developed DSA. Patients who cleared their DSA had a better CR-free and overall survival compared to patients who failed to clear their DSA. Combined treatment with rituximab and IVIG proved to be superior compared to IVIG alone (128). Therefore, preemptive antibody-directed treatment may mitigate the risk of CR associated with DSA. However, evidence is scarce and placebo controlled trials are desperately needed.

\section{Infections}

Since the lung is one of the only organs in direct contact with the external environment, the lung is uniquely susceptible to microbial invasion, a part from the risk of donor-derived infections such as for instance by CMV. Therefore, infection of the lung allografts with microorganisms is very frequent and multiple infections are known to be associated with the development of CR (129).

\section{CMV}

Since LTx donor and LTx recipient are most not matched for CMV status, reactivation of CMV after LTx is common. In the past, early survival after LTx was frequently hampered by CMV infections (130). Meanwhile, a preventive therapy with ganciclovir or valganciclovir has shown to reduce the cumulative incidence of CMV-related events and to ameliorate CR-free and overall survival in LTx patients (131-134). However, despite this improvement, CR-free and overall survival is still reduced in CMV-mismatched LTx recipients in comparison to matched patients despite ganciclovir/ganciclovir prophylaxis, suggesting that CMV prophylaxis is not optimized yet (135). Zamora et al. could show that ganciclovir/valganciclovir prophylaxis should be continued for at least 180 days after LTx to significantly reduce the incidence of CMV disease and hence CR-free and overall survival. However, optimal duration and timing of this preventive therapy remains unknown (136).

Multiple retrospective studies could demonstrate superiority of a combined preventive regimen consisting of CMV hyperimmune globulins (CMV IG) in addition 
to ganciclovir/valganciclovir in comparison to ganciclovir/ valganciclovir alone in high risk patients influencing CR incidence and overall survival $(135,137,138)$. Moreover, Solidoro et al. showed reduced AR and lymphocytic bronchiolitis, as well as a lower prevalence of Epstein-Barr virus (EBV) and combined $\mathrm{CMV}$ and $\mathrm{EBV}$ infections with a combined preventive therapy (139).

In the future, prospective randomized clinical trials are needed to evaluate efficacy, cost-effectiveness and timing of either prolonged ganciclovir/valganciclovir prophylaxis, or combined CMV prophylaxis on CR prevention.

\section{Respiratory syncytial virus (RSV)}

In LTx patients, RSV is one of the most common community-acquired respiratory virus infections. Lower respiratory tract infections by RSV are associated with the development of CR and a worse long-term survival (140-143). In the past, RSV has been treated off-label with ribavirin, corticosteroids, palivizumab or immunoglobulins. Nevertheless, none of these treatments was proven to prevent subsequent development of CR (144-146). However, recently a multicenter randomized placebocontrolled trial of Gottlieb et al. using inhaled ALN-RSV01 was able to demonstrate a lower incidence of new onset or progressive CR after RSV infection, compared to placebo. ALN-RSV01 is a siRNA targeting the RSV nucleocapsid messenger RNA, preventing formation of the nucleocapsid protein and thereby reducing viral replication. ALN-RSV01 may provide a novel preventive treatment approach for decreasing the incidence of RSV-related CR $(147,148)$.

\section{Pseudomonas spp.}

Colonization or infection with Pseudomonas spp. after LTx is an established risk factor for the development of CR and is associated with worse CR-free and overall survival (129,149-151). Pseudomonas spp. induce direct tissue damage, immune-mediated injury and fibroblast proliferation, finally leading to complete obstruction of the airways (152). This process is orchestrated by intercellular quorum-sensing signaling molecules (QSM), which have an intrinsic immunomodulatory capacity resulting in suppressed T-cell proliferation, chemokine and cytokine release an neutrophil chemotaxis $(149,153)$.

Azithromycin has immunomodulatory properties and inhibits the production of cytokines, proteases and quorum sensing molecules. Therefore, azithromycin may be an effective preventive therapy for CR in patients colonized with Pseudomonas after LTx (149). However, more prospective trials are needed. Aerosolized antipseudomonals (AAP) have demonstrated, in a single center retrospective trial, to protect LTx patients not suffering from cystic fibrosis (CF) against recurrent infections with Pseudomonas spp., without having an effect on CR-free and overall survival (154). AAP after LTx have also shown to improve maintenance of lower airway sterility concerning Pseudomonas spp. in CF and have possibly a beneficial effect on AR and CR occurrence or progression $(155,156)$. However, randomized controlled trials with AAP as a preventive treatment are lacking.

\section{Aspergillus spp.}

Colonization and infection of the lungs with Aspergillus spp. have been identified as a distinct risk factor for CR $(129,157)$. Since deposition of Aspergillus conidia in the small airways is involved in Aspergillus-driven development of CR, in particular small conidia Aspergillus spp. are at risk for the development of CR (158). In contradiction, Peghin et al. could not confirm the association between colonization and infection with Aspergillus spp. and subsequent development of CR (159).

Nebulized liposomal amphotericin B decreases the incidence of infection and colonization with Aspergillus spp. and therefore may prevent CR $(159,160)$. Voriconazole prophylaxis may also be used as a preventive strategy for Aspergillus in LTx patients, but voriconazole is associated with liver enzyme abnormalities and the development of cutaneous squamous cell carcinoma $(161,162)$. Yet, studies evaluating the efficacy of anti-Aspergillus prophylaxis are scarce and generally underpowered to detect a significant reduction in CR incidence after Aspergillus prophylaxis after LTx.

\section{Gastroesophageal reflux}

Gastroesophageal reflux disease (GERD) is highly prevalent in patients with end-stage lung diseases awaiting LTx (163). Moreover, LTx recipients are prone to develop GERD after surgery due to post-operative iatrogenic vagal innervation, impaired cough reflexes and mucociliary clearance, and reduced gastric motility induced by immunosuppressive drugs such as calcineurin inhibitors (164). Acid and non-acidic reflux are known non-alloimmune risk factors for the development of CR by causing repetitive epithelial injury and are associated with worse pulmonary function (165-168).

Pharmacological treatment of reflux consists of histamine-2 receptor blockers, proton pomp inhibitors 
(PPI) and prokinetic agents to support gastric motility (169). Evidence for medical treatment of GERD and gastric aspiration is scarce. A therapy with a PPI could not reduce pepsin as a surrogate marker of aspiration in BAL fluid of LTx patients (166). However, azithromycin was demonstrated to decrease reflux, proximal reflux episodes and esophageal acid exposure. Bile acid levels in BAL were significantly reduced as well (170).

Fundoplication surgery (e.g., Nissen or Toupet fundoplication) is a last surgical option to prevent gastric aspiration. In a study of 30 pediatric LTx recipients, reflux burden and fundoplication were not associated with CRfree and overall survival (171). However, other studies demonstrated a decrease in AR and an improvement or stabilization in CR-free and overall survival after antireflux surgery $(169,172-178)$. These beneficial effects of fundoplication seems to be based on improving the immune environment in the lungs of LTx patients (179). Since only retrospective observational studies and case series are available, and thus more evidence is needed, surgery should only be performed in well-selected patients with high evidence for GERD.

\section{Sinus surgery}

Patients with CF frequently suffer from chronic rhinosinusitis. The sinuses of these patients can be considered as a reservoir for bacteria, which can spread to the lower respiratory tract, where they can cause allograft colonization and infection $(180,181)$. The upper and lower airways of patients with $\mathrm{CF}$ are also more often colonized with Pseudomonas spp. than the airways of LTx recipients with other underlying diseases (182). Since Pseudomonas spp. are known to be associated with the development of CR, it is possible that chronic rhinosinusitis with Pseudomonas spp. plays a role in the development of CR in LTx recipients with CF (149).

Extensive sinus surgery, consisting of endoscopic frontospheno-ethmoidectomy combined with daily nasal rinsing with a saline solution, after LTx in CF patients may lead to a decrease of approximately $30 \%$ in concurrent colonization of the higher and lower airways with Pseudomonas spp. and other bacteria (183-185). A significant decrease in clinically relevant pulmonary infections has also been demonstrated (183). Whereas Holzmann et al. could only show a trend towards a lower incidence of $\mathrm{CR}$ after sinus surgery and daily nasal care after LTx in CF patients, Vital et al. could reveal a significant decrease of CR (183-185). Leung et al. could not prove an effect on overall nor on CR-free survival, but the protocol of this study included pretransplant sinus surgery limited to the maxillary sinus and the ethmoid in CF patients and lacked a postoperative nasal care program (186).

\section{Conclusions}

Long-term survival after LTx is mainly limited by the development of CR. Since therapeutic strategies have been largely unsuccessful, prevention of CR is an important and challenging therapeutic approach. CR is a term covering different phenotypes including BOS and RAS. Since these different phenotypes have different clinical characteristics, different pathophysiological mechanisms and survival differences, different prevention and treatment strategies will be needed. Therefore, a personalized, tailored therapeutic regimen will probably be the most effective approach in these LTx patients. Despite the importance of preventive strategies, clear evidence is scarce and more randomized controlled trials are desperately needed.

\section{Acknowledgements}

Funding: Following authors are supported by a research fellowship- $\mathrm{R}$ Vos is senior clinical research fellow of the Research Foundation Flanders (FWO), Belgium and he is supported by a research grant of UZ Leuven, Belgium (STG15/023); SE Verleden is a post-doctoral research fellow of the Research Foundation Flanders (FWO), Belgium; BM Vanaudenaerde and GM Verleden are supported by a research grant of KU Leuven, Belgium (C2/15/030).

\section{Footnote}

Conflicts of Interest: The authors have no conflicts of interest to declare.

\section{References}

1. Lund LH, Edwards LB, Dipchand AI, et al. The Registry of the International Society for Heart and Lung Transplantation: Thirty-third Adult Heart Transplantation Report-2016; Focus Theme: Primary Diagnostic Indications for Transplant. J Heart Lung Transplant 2016;35:1158-69.

2. Verleden GM, Dupont LJ, Van Raemdonck DE, et al. Lung transplantation: a 15-year single-center experience. 
Clin Transpl 2007:121-30.

3. Sayegh $\mathrm{MH}$, Carpenter CB. Transplantation 50 years later--progress, challenges, and promises. N Engl J Med 2004;351:2761-6.

4. Opelz G, Döhler B, Ruhenstroth A, et al. The collaborative transplant study registry. Transplant Rev (Orlando) 2013;27:43-5.

5. Verleden GM, Vos R, Vanaudenaerde B, et al. Current views on chronic rejection after lung transplantation. Transpl Int 2015;28:1131-9.

6. Sato M, Waddell TK, Wagnetz $\mathrm{U}$, et al. Restrictive allograft syndrome (RAS): a novel form of chronic lung allograft dysfunction. J Heart Lung Transplant 2011;30:735-42.

7. Belperio JA, Weigt SS, Fishbein MC, et al. Chronic lung allograft rejection: mechanisms and therapy. Proc Am Thorac Soc 2009;6:108-21.

8. Hopkins PM, McNeil K. Evidence for immunosuppression in lung transplantation. Curr Opin Organ Transplant 2008; $13: 477-83$.

9. Snell GI, Westall GP, Paraskeva MA. Immunosuppression and allograft rejection following lung transplantation: evidence to date. Drugs 2013;73:1793-813.

10. Scott AI, Sharples LD, Stewart S. Bronchiolitis obliterans syndrome: risk factors and therapeutic strategies. Drugs 2005;65:761-71

11. Vos R, Verleden SE, Verleden GM. Chronic lung allograft dysfunction: evolving practice. Curr Opin Organ Transplant 2015;20:483-91.

12. Sharples LD, McNeil K, Stewart S, et al. Risk factors for bronchiolitis obliterans: a systematic review of recent publications. J Heart Lung Transplant 2002;21:271-81.

13. Knoop C, Haverich A, Fischer S. Immunosuppressive therapy after human lung transplantation. Eur Respir J 2004;23:159-71.

14. Ailawadi G, Smith PW, Oka T, et al. Effects of induction immunosuppression regimen on acute rejection, bronchiolitis obliterans, and survival after lung transplantation. J Thorac Cardiovasc Surg 2008;135:594-602.

15. Garrity ER Jr, Villanueva J, Bhorade SM, et al. Low rate of acute lung allograft rejection after the use of daclizumab, an interleukin 2 receptor antibody. Transplantation 2001;71:773-7.

16. Lischke R, Simonek J, Davidová R, et al. Induction therapy in lung transplantation: initial single-center experience comparing daclizumab and antithymocyte globulin. Transplant Proc 2007;39:205-12.
17. Hachem RR, Chakinala MM, Yusen RD, et al. A comparison of basiliximab and anti-thymocyte globulin as induction agents after lung transplantation. J Heart Lung Transplant 2005;24:1320-6.

18. Burton CM, Andersen CB, Jensen AS, et al. The incidence of acute cellular rejection after lung transplantation: a comparative study of anti-thymocyte globulin and daclizumab. J Heart Lung Transplant 2006;25:638-47.

19. Brock MV, Borja MC, Ferber L, et al. Induction therapy in lung transplantation: a prospective, controlled clinical trial comparing OKT3, anti-thymocyte globulin, and daclizumab. J Heart Lung Transplant 2001;20:1282-90.

20. Palmer SM, Miralles AP, Lawrence CM, et al. Rabbit antithymocyte globulin decreases acute rejection after lung transplantation: results of a randomized, prospective study. Chest 1999;116:127-33.

21. Hartwig MG, Snyder LD, Appel JZ 3rd, et al. Rabbit anti-thymocyte globulin induction therapy does not prolong survival after lung transplantation. J Heart Lung Transplant 2008;27:547-53.

22. Barlow CW, Moon MR, Green GR, et al. Rabbit antithymocyte globulin versus OKT3 induction therapy after heart-lung and lung transplantation: effect on survival, rejection, infection, and obliterative bronchiolitis. Transpl Int 2001;14:234-9.

23. Wehman B, Griffith BP, Balwan A, et al. Long-term outcomes following alemtuzumab induction in lung transplantation. Heart Surg Forum 2013;16:E252-6.

24. Shyu S, Dew MA, Pilewski JM, et al. Five-year outcomes with alemtuzumab induction after lung transplantation. J Heart Lung Transplant 2011;30:743-54.

25. Penninga L, Møller CH, Penninga EI, et al. Antibody induction therapy for lung transplant recipients. Cochrane Database Syst Rev 2013;(11):CD008927.

26. van Sandwijk MS, Bemelman FJ, Ten Berge IJ. Immunosuppressive drugs after solid organ transplantation. Neth J Med 2013;71:281-9.

27. Taylor AL, Watson CJ, Bradley JA. Immunosuppressive agents in solid organ transplantation: Mechanisms of action and therapeutic efficacy. Crit Rev Oncol Hematol 2005;56:23-46.

28. Vogelmeier CF, Criner GJ, Martinez FJ, et al. Global Strategy for the Diagnosis, Management and Prevention of Chronic Obstructive Lung Disease 2017 Report: GOLD Executive Summary. Respirology 2017;22:575-601.

29. (*NEW) 2017 GINA Report: Global Strategy for Asthma Management and Prevention. Global Initiative for Asthma - GINA. Available online: http://ginasthma.org/2017- 
gina-report-global-strategy-for-asthma-management-andprevention/

30. Whitford H, Orsida B, Kotsimbos T, et al. Bronchoalveolar lavage cellular profiles in lung transplantation: the effect of inhaled corticosteroids. Ann Transplant 2000;5:31-7.

31. Whitford H, Walters EH, Levvey B, et al. Addition of inhaled corticosteroids to systemic immunosuppression after lung transplantation: a double-blind, placebocontrolled trial. Transplantation 2002;73:1793-9.

32. Halloran P, Mathew T, Tomlanovich S, et al. Mycophenolate mofetil in renal allograft recipients: a pooled efficacy analysis of three randomized, doubleblind, clinical studies in prevention of rejection. The International Mycophenolate Mofetil Renal Transplant Study Groups. Transplantation 1997;63:39-47.

33. Kobashigawa J, Miller L, Renlund D, et al. A randomized active-controlled trial of mycophenolate mofetil in heart transplant recipients. Mycophenolate Mofetil Investigators. Transplantation 1998;66:507-15.

34. Ross DJ, Waters PF, Levine M, et al. Mycophenolate mofetil versus azathioprine immunosuppressive regimens after lung transplantation: preliminary experience. J Heart Lung Transplant 1998;17:768-74.

35. Zuckermann A, Klepetko W, Birsan T, et al. Comparison between mycophenolate mofetil- and azathioprine-based immunosuppressions in clinical lung transplantation. J Heart Lung Transplant 1999;18:432-40.

36. O'Hair DP, Cantu E, McGregor C, et al. Preliminary experience with mycophenolate mofetil used after lung transplantation. J Heart Lung Transplant 1998;17:864-8.

37. Speich R, Schneider S, Hofer M, et al. Mycophenolate mofetil reduces alveolar inflammation, acute rejection and graft loss due to bronchiolitis obliterans syndrome after lung transplantation. Pulm Pharmacol Ther 2010;23:445-9.

38. Palmer SM, Baz MA, Sanders L, et al. Results of a randomized, prospective, multicenter trial of mycophenolate mofetil versus azathioprine in the prevention of acute lung allograft rejection. Transplantation 2001;71:1772-6.

39. Glanville AR, Aboyoun C, Klepetko W, et al. Threeyear results of an investigator-driven multicenter, international, randomized open-label de novo trial to prevent BOS after lung transplantation. J Heart Lung Transplant 2015;34:16-25.

40. Enderby C, Keller CA. An overview of immunosuppression in solid organ transplantation. Am J Manag Care 2015;21:s12-23.
41. Keenan RJ, Konishi H, Kawai A, et al. Clinical trial of tacrolimus versus cyclosporine in lung transplantation. Ann Thorac Surg 1995;60:580-4; discussion 584-5.

42. Treede H, Klepetko W, Reichenspurner H, et al. Tacrolimus versus cyclosporine after lung transplantation: a prospective, open, randomized two-center trial comparing two different immunosuppressive protocols. J Heart Lung Transplant 2001;20:511-7.

43. Treede H, Glanville AR, Klepetko W, et al. Tacrolimus and cyclosporine have differential effects on the risk of development of bronchiolitis obliterans syndrome: results of a prospective, randomized international trial in lung transplantation. J Heart Lung Transplant 2012;31:797-804.

44. Zuckermann A, Reichenspurner H, Birsan T, et al. Cyclosporine A versus tacrolimus in combination with mycophenolate mofetil and steroids as primary immunosuppression after lung transplantation: one-year results of a 2-center prospective randomized trial. J Thorac Cardiovasc Surg 2003;125:891-900.

45. Penninga L, Penninga EI, Møller CH, et al. Tacrolimus versus cyclosporin as primary immunosuppression for lung transplant recipients. Cochrane Database Syst Rev 2013;(5):CD008817.

46. Hachem RR, Yusen RD, Chakinala MM, et al. A randomized controlled trial of tacrolimus versus cyclosporine after lung transplantation. J Heart Lung Transplant 2007;26:1012-8.

47. Iacono AT, Johnson BA, Grgurich WF, et al. A randomized trial of inhaled cyclosporine in lung-transplant recipients. N Engl J Med 2006;354:141-50.

48. Corcoran TE, Smaldone GC, Dauber JH, et al. Preservation of post-transplant lung function with aerosol cyclosporin. Eur Respir J 2004;23:378-83.

49. DeCamp MM Jr. Inhaled cyclosporine--a breath of fresh air? N Engl J Med 2006;354:191-3.

50. Johnson BA, Zamora MR, Budev MM, et al. 172 Cyclosporine Inhalation Solution Does Not Improve Bronchiolitis Obliterans Syndrome-Free Survival Following Lung Transplant: Results from the CYCLIST Trial. J Heart Lung Transplant 2012;31:S66.

51. Snell GI, Valentine VG, Vitulo P, et al. Everolimus versus azathioprine in maintenance lung transplant recipients: an international, randomized, double-blind clinical trial. Am J Transplant 2006;6:169-77.

52. Bhorade S, Ahya VN, Baz MA, et al. Comparison of sirolimus with azathioprine in a tacrolimus-based immunosuppressive regimen in lung transplantation. Am J 
Respir Crit Care Med 2011;183:379-87.

53. Sacher VY, Fertel D, Srivastava K, et al. Effects of prophylactic use of sirolimus on bronchiolitis obliterans syndrome development in lung transplant recipients. Ann Thorac Surg 2014;97:268-74.

54. King-Biggs MB, Dunitz JM, Park SJ, et al. Airway anastomotic dehiscence associated with use of sirolimus immediately after lung transplantation. Transplantation 2003;75:1437-43.

55. Gullestad L, Eiskjaer H, Gustafsson F, et al. Long-term outcomes of thoracic transplant recipients following conversion to everolimus with reduced calcineurin inhibitor in a multicenter, open-label, randomized trial. Transpl Int 2016;29:819-29.

56. Shitrit D, Rahamimov R, Gidon S, et al. Use of sirolimus and low-dose calcineurin inhibitor in lung transplant recipients with renal impairment: results of a controlled pilot study. Kidney Int 2005;67:1471-5.

57. Ghassemieh B, Ahya VN, Baz MA, et al. Decreased incidence of cytomegalovirus infection with sirolimus in a post hoc randomized, multicenter study in lung transplantation. J Heart Lung Transplant 2013;32:701-6.

58. Retsema J, Fu W. Macrolides: structures and microbial targets. Int J Antimicrob Agents 2001;18 Suppl 1:S3-10.

59. Vos R, Vanaudenaerde BM, Verleden SE, et al. Antiinflammatory and immunomodulatory properties of azithromycin involved in treatment and prevention of chronic lung allograft rejection. Transplantation 2012;94:101-9.

60. Gerhardt SG, McDyer JF, Girgis RE, et al. Maintenance azithromycin therapy for bronchiolitis obliterans syndrome: results of a pilot study. Am J Respir Crit Care Med 2003;168:121-5.

61. Verleden GM, Dupont LJ. Azithromycin therapy for patients with bronchiolitis obliterans syndrome after lung transplantation. Transplantation 2004;77:1465-7.

62. Yates B, Murphy DM, Forrest IA, et al. Azithromycin reverses airflow obstruction in established bronchiolitis obliterans syndrome. Am J Respir Crit Care Med 2005;172:772-5.

63. Shitrit D, Bendayan D, Gidon S, et al. Long-term azithromycin use for treatment of bronchiolitis obliterans syndrome in lung transplant recipients. J Heart Lung Transplant 2005;24:1440-3.

64. Porhownik NR, Batobara W, Kepron W, et al. Effect of maintenance azithromycin on established bronchiolitis obliterans syndrome in lung transplant patients. Can Respir J 2008;15:199-202.
65. Gottlieb J, Szangolies J, Koehnlein T, et al. Long-term azithromycin for bronchiolitis obliterans syndrome after lung transplantation. Transplantation 2008;85:36-41.

66. Verleden GM, Vanaudenaerde BM, Dupont LJ, et al. Azithromycin reduces airway neutrophilia and interleukin-8 in patients with bronchiolitis obliterans syndrome. Am J Respir Crit Care Med 2006;174:566-70.

67. Vanaudenaerde BM, Meyts I, Vos R, et al. A dichotomy in bronchiolitis obliterans syndrome after lung transplantation revealed by azithromycin therapy. Eur Respir J 2008;32:832-43.

68. Vos R, Vanaudenaerde BM, Ottevaere A, et al. Longterm azithromycin therapy for bronchiolitis obliterans syndrome: divide and conquer? J Heart Lung Transplant 2010;29:1358-68.

69. Jain R, Hachem RR, Morrell MR, et al. Azithromycin is associated with increased survival in lung transplant recipients with bronchiolitis obliterans syndrome. J Heart Lung Transplant 2010;29:531-7.

70. Corris PA, Ryan VA, Small T, et al. A randomised controlled trial of azithromycin therapy in bronchiolitis obliterans syndrome (BOS) post lung transplantation. Thorax 2015;70:442-50.

71. Verleden SE, Vandermeulen E, Ruttens D, et al. Neutrophilic reversible allograft dysfunction (NRAD) and restrictive allograft syndrome (RAS). Semin Respir Crit Care Med 2013;34:352-60.

72. Meyer KC, Raghu G, Verleden GM, et al. An international ISHLT/ATS/ERS clinical practice guideline: diagnosis and management of bronchiolitis obliterans syndrome. Eur Respir J 2014;44:1479-503.

73. Vos R, Vanaudenaerde BM, Verleden SE, et al. A randomised controlled trial of azithromycin to prevent chronic rejection after lung transplantation. Eur Respir J 2011;37:164-72.

74. Ruttens D, Verleden SE, Vandermeulen E, et al. Prophylactic Azithromycin Therapy After Lung Transplantation: Post hoc Analysis of a Randomized Controlled Trial. Am J Transplant 2016;16:254-61.

75. Li H, Liu DH, Chen LL, et al. Meta-analysis of the adverse effects of long-term azithromycin use in patients with chronic lung diseases. Antimicrob Agents Chemother 2014;58:511-7.

76. Svanström H, Pasternak B, Hviid A. Use of azithromycin and death from cardiovascular causes. N Engl J Med 2013;368:1704-12.

77. Albert RK, Connett J, Bailey WC, et al. Azithromycin for prevention of exacerbations of COPD. N Engl J Med 
2011;365:689-98.

78. Lopes Dos Santos Santiago G, Brusselle G, Dauwe K, et al. Influence of chronic azithromycin treatment on the composition of the oropharyngeal microbial community in patients with severe asthma. BMC Microbiol 2017;17:109.

79. Benden C, Boehler A. Long-term clarithromycin therapy in the management of lung transplant recipients. Transplantation 2009;87:1538-40.

80. Dhillon GS, Valentine VG, Levitt J, et al. Clarithromycin for prevention of bronchiolitis obliterans syndrome in lung allograft recipients. Clin Transplant 2012;26:105-10.

81. Ibrahim RB, Abella EM, Chandrasekar PH. Tacrolimusclarithromycin interaction in a patient receiving bone marrow transplantation. Ann Pharmacother 2002;36:1971-2.

82. Kunicki PK, Sobieszczańska-Małek M. Pharmacokinetic interaction between tacrolimus and clarithromycin in a heart transplant patient. Ther Drug Monit 2005;27:107-8.

83. Ramsay CF, Sullivan P, Gizycki M, et al. Montelukast and bronchial inflammation in asthma: a randomised, double-blind placebo-controlled trial. Respir Med 2009; 103:995-1003.

84. Or R, Gesundheit B, Resnick I, et al. Sparing effect by montelukast treatment for chronic graft versus host disease: a pilot study. Transplantation 2007;83:577-81.

85. Verleden GM, Verleden SE, Vos R, et al. Montelukast for bronchiolitis obliterans syndrome after lung transplantation: a pilot study. Transpl Int 2011;24:651-6.

86. Mach F. Statins as novel immunomodulators: from cell to potential clinical benefit. Thromb Haemost 2003;90:607-10.

87. Verleden GM, Vos R. Statins in lung transplantation: A treatment option for every patient? J Heart Lung Transplant 2017;36:936-7.

88. Johnson BA, Iacono AT, Zeevi A, et al. Statin use is associated with improved function and survival of lung allografts. Am J Respir Crit Care Med 2003;167:1271-8.

89. Li Y, Gottlieb J, Ma D, et al. Graft-protective effects of the $\mathrm{HMG}-\mathrm{CoA}$ reductase inhibitor pravastatin after lung transplantation--a propensity score analysis with 23 years of follow-up. Transplantation 2011;92:486-92.

90. Raphael J, Collins SR, Wang XQ, et al. Perioperative statin use is associated with decreased incidence of primary graft dysfunction after lung transplantation. J Heart Lung Transplant 2017;36:948-56.

91. McAuley DF, Laffey JG, O'Kane CM, et al. Simvastatin in the acute respiratory distress syndrome. N Engl J Med 2014;371:1695-703.
92. Solidoro P, Bellocchia M, Facchini F. The immunobiological and clinical role of vitamin $\mathrm{D}$ in obstructive lung diseases. Minerva Med 2016;107:12-9.

93. Janssens W, Bouillon R, Claes B, et al. Vitamin D deficiency is highly prevalent in COPD and correlates with variants in the vitamin D-binding gene. Thorax 2010;65:215-20.

94. Vos R, Ruttens D, Verleden SE, et al. High-dose vitamin $\mathrm{D}$ after lung transplantation: A randomized trial. J Heart Lung Transplant 2017;36:897-905.

95. Greer M, Dierich M, De Wall C, et al. Phenotyping established chronic lung allograft dysfunction predicts extracorporeal photopheresis response in lung transplant patients. Am J Transplant 2013;13:911-8.

96. Del Fante C, Scudeller L, Oggionni T, et al. Long-Term Off-Line Extracorporeal Photochemotherapy in Patients with Chronic Lung Allograft Rejection Not Responsive to Conventional Treatment: A 10-Year Single-Centre Analysis. Respiration 2015;90:118-28.

97. Jaksch P, Scheed A, Keplinger M, et al. A prospective interventional study on the use of extracorporeal photopheresis in patients with bronchiolitis obliterans syndrome after lung transplantation. J Heart Lung Transplant 2012;31:950-7.

98. Morrell MR, Despotis GJ, Lublin DM, et al. The efficacy of photopheresis for bronchiolitis obliterans syndrome after lung transplantation. J Heart Lung Transplant 2010;29:424-31.

99. Benden C, Speich R, Hofbauer GF, et al. Extracorporeal photopheresis after lung transplantation: a 10-year singlecenter experience. Transplantation 2008;86:1625-7.

100.Isenring B, Robinson C, Buergi U, et al. Lung transplant recipients on long-term extracorporeal photopheresis. Clin Transplant 2017;31.

101. Christie JD, Carby M, Bag R, et al. Report of the ISHLT Working Group on Primary Lung Graft Dysfunction part II: definition. A consensus statement of the International Society for Heart and Lung Transplantation. J Heart Lung Transplant 2005;24:1454-9.

102. Meyers BF, de la Morena M, Sweet SC, et al. Primary graft dysfunction and other selected complications of lung transplantation: A single-center experience of 983 patients. J Thorac Cardiovasc Surg 2005;129:1421-9.

103. Fiser SM, Tribble CG, Long SM, et al. Ischemiareperfusion injury after lung transplantation increases risk of late bronchiolitis obliterans syndrome. Ann Thorac Surg 2002;73:1041-7; discussion 1047-8.

104. Christie JD, Kotloff RM, Ahya VN, et al. The 
effect of primary graft dysfunction on survival after lung transplantation. Am J Respir Crit Care Med 2005;171:1312-6.

105. Suzuki Y, Cantu E, Christie JD. Primary graft dysfunction. Semin Respir Crit Care Med 2013;34:305-19.

106. Gohrbandt B, Simon AR, Warnecke G, et al. Lung Preservation With Perfadex or Celsior in Clinical Transplantation: A Retrospective Single-Center Analysis of Outcomes. Transplantation 2015;99:1933-9.

107.Latchana N, Peck JR, Whitson B, et al. Preservation solutions for cardiac and pulmonary donor grafts: a review of the current literature. J Thorac Dis 2014;6:1143-9.

108. Mohamed MS. Could Ex Vivo Lung Perfusion Be a Platform to Decrease the Incidence of Chronic Lung Allograft Dysfunction? Arch Med Res 2015;46:240-3.

109. Martens A, Ordies S, Vanaudenaerde BM, et al. Immunoregulatory effects of multipotent adult progenitor cells in a porcine ex vivo lung perfusion model. Stem Cell Res Ther 2017;8:159.

110. Tikkanen JM, Cypel M, Machuca TN, et al. Functional outcomes and quality of life after normothermic ex vivo lung perfusion lung transplantation. J Heart Lung Transplant 2015;34:547-56.

111. Stewart S, Fishbein MC, Snell GI, et al. Revision of the 1996 working formulation for the standardization of nomenclature in the diagnosis of lung rejection. J Heart Lung Transplant 2007;26:1229-42.

112. Bando K, Paradis IL, Similo S, et al. Obliterative bronchiolitis after lung and heart-lung transplantation. An analysis of risk factors and management. J Thorac Cardiovasc Surg 1995;110:4-13; discussion 13-4.

113. Husain AN, Siddiqui MT, Holmes EW, et al. Analysis of risk factors for the development of bronchiolitis obliterans syndrome. Am J Respir Crit Care Med 1999;159:829-33.

114. Girgis RE, Tu I, Berry GJ, et al. Risk factors for the development of obliterative bronchiolitis after lung transplantation. J Heart Lung Transplant 1996;15:1200-8.

115. Glanville AR, Aboyoun CL, Havryk A, et al. Severity of lymphocytic bronchiolitis predicts long-term outcome after lung transplantation. Am J Respir Crit Care Med 2008; 177:1033-40.

116. Hopkins PM, Aboyoun CL, Chhajed PN, et al. Association of minimal rejection in lung transplant recipients with obliterative bronchiolitis. Am J Respir Crit Care Med 2004;170:1022-6.

117. Guilinger RA, Paradis IL, Dauber JH, et al. The importance of bronchoscopy with transbronchial biopsy and bronchoalveolar lavage in the management of lung transplant recipients. Am J Respir Crit Care Med 1995;152:2037-43.

118. Vandermeulen E, Verleden SE, Ruttens D, et al. BAL neutrophilia in azithromycin-treated lung transplant recipients: Clinical significance. Transpl Immunol 2015;33:37-44.

119. De Soyza A, Fisher AJ, Small T, et al. Inhaled corticosteroids and the treatment of lymphocytic bronchiolitis following lung transplantation. Am J Respir Crit Care Med 2001;164:1209-12.

120. Hachem RR, Tiriveedhi V, Patterson GA, et al. Antibodies to $\mathrm{K}-\alpha 1$ tubulin and collagen $\mathrm{V}$ are associated with chronic rejection after lung transplantation. Am J Transplant 2012;12:2164-71.

121. Tikkanen JM, Singer LG, Kim SJ, et al. De Novo DQ Donor-Specific Antibodies Are Associated with Chronic Lung Allograft Dysfunction after Lung Transplantation. Am J Respir Crit Care Med 2016;194:596-606.

122.Morrell MR, Pilewski JM, Gries CJ, et al. De novo donorspecific HLA antibodies are associated with early and high-grade bronchiolitis obliterans syndrome and death after lung transplantation. J Heart Lung Transplant 2014;33:1288-94.

123. Snyder LD, Wang Z, Chen DF, et al. Implications for human leukocyte antigen antibodies after lung transplantation: a 10-year experience in 441 patients. Chest 2013;144:226-33.

124. Safavi S, Robinson DR, Soresi S, et al. De novo donor HLA-specific antibodies predict development of bronchiolitis obliterans syndrome after lung transplantation. J Heart Lung Transplant 2014;33:1273-81.

125. Girnita AL, McCurry KR, Iacono AT, et al. HLA-specific antibodies are associated with high-grade and persistentrecurrent lung allograft acute rejection. J Heart Lung Transplant 2004;23:1135-41.

126. Girnita AL, Duquesnoy R, Yousem SA, et al. HLA-specific antibodies are risk factors for lymphocytic bronchiolitis and chronic lung allograft dysfunction. Am J Transplant 2005;5:131-8.

127. Snyder LD, Gray AL, Reynolds JM, et al. Antibody desensitization therapy in highly sensitized lung transplant candidates. Am J Transplant 2014;14:849-56.

128. Hachem RR, Yusen RD, Meyers BF, et al. Anti-human leukocyte antigen antibodies and preemptive antibodydirected therapy after lung transplantation. J Heart Lung Transplant 2010;29:973-80.

129. Martin-Gandul C, Mueller NJ, Pascual M, et al. The 
Impact of Infection on Chronic Allograft Dysfunction and Allograft Survival After Solid Organ Transplantation. Am J Transplant 2015;15:3024-40.

130.Duncan AJ, Dummer JS, Paradis IL, et al. Cytomegalovirus infection and survival in lung transplant recipients. J Heart Lung Transplant 1991;10:638-44; discussion 645-6.

131. Speich R, Thurnheer R, Gaspert A, et al. Efficacy and cost effectiveness of oral ganciclovir in the prevention of cytomegalovirus disease after lung transplantation. Transplantation 1999;67:315-20.

132. Soghikian MV, Valentine VG, Berry GJ, et al. Impact of ganciclovir prophylaxis on heart-lung and lung transplant recipients. J Heart Lung Transplant 1996;15:881-7.

133.Palmer SM, Grinnan DC, Diane Reams B, et al. Delay of CMV infection in high-risk CMV mismatch lung transplant recipients due to prophylaxis with oral ganciclovir. Clin Transplant 2004;18:179-85.

134. Chmiel C, Speich R, Hofer M, et al. Ganciclovir/ valganciclovir prophylaxis decreases cytomegalovirusrelated events and bronchiolitis obliterans syndrome after lung transplantation. Clin Infect Dis 2008;46:831-9.

135. Ruttmann E, Geltner C, Bucher B, et al. Combined $\mathrm{CMV}$ prophylaxis improves outcome and reduces the risk for bronchiolitis obliterans syndrome (BOS) after lung transplantation. Transplantation 2006;81:1415-20.

136.Zamora MR, Nicolls MR, Hodges TN, et al. Following universal prophylaxis with intravenous ganciclovir and cytomegalovirus immune globulin, valganciclovir is safe and effective for prevention of CMV infection following lung transplantation. Am J Transplant 2004;4:1635-42.

137. Valantine HA, Luikart H, Doyle R, et al. Impact of cytomegalovirus hyperimmune globulin on outcome after cardiothoracic transplantation: a comparative study of combined prophylaxis with CMV hyperimmune globulin plus ganciclovir versus ganciclovir alone. Transplantation 2001;72:1647-52.

138. Weill D, Lock BJ, Wewers DL, et al. Combination prophylaxis with ganciclovir and cytomegalovirus (CMV) immune globulin after lung transplantation: effective CMV prevention following daclizumab induction. Am J Transplant 2003;3:492-6.

139. Solidoro P, Libertucci D, Delsedime L, et al. Combined cytomegalovirus prophylaxis in lung transplantation: effects on acute rejection, lymphocytic bronchitis/ bronchiolitis, and herpesvirus infections. Transplant Proc 2008;40:2013-4.

140. Glezen WP, Greenberg SB, Atmar RL, et al. Impact of respiratory virus infections on persons with chronic underlying conditions. JAMA 2000;283:499-505.

141. Khalifah AP, Hachem RR, Chakinala MM, et al. Respiratory viral infections are a distinct risk for bronchiolitis obliterans syndrome and death. Am J Respir Crit Care Med 2004;170:181-7.

142. Kumar D, Erdman D, Keshavjee S, et al. Clinical impact of community-acquired respiratory viruses on bronchiolitis obliterans after lung transplant. Am J Transplant 2005;5:2031-6.

143. Billings JL, Hertz MI, Savik K, et al. Respiratory viruses and chronic rejection in lung transplant recipients. J Heart Lung Transplant 2002;21:559-66.

144. Pelaez A, Lyon GM, Force SD, et al. Efficacy of oral ribavirin in lung transplant patients with respiratory syncytial virus lower respiratory tract infection. J Heart Lung Transplant 2009;28:67-71.

145. Danziger-Isakov LA, Arslan D, Sweet S, et al. RSV prevention and treatment in pediatric lung transplant patients: a survey of current practices among the International Pediatric Lung Transplant Collaborative. Pediatr Transplant 2012;16:638-44.

146. Liu V, Dhillon GS, Weill D. A multi-drug regimen for respiratory syncytial virus and parainfluenza virus infections in adult lung and heart-lung transplant recipients. Transpl Infect Dis 2010;12:38-44.

147. Gottlieb J, Zamora MR, Hodges T, et al. ALN-RSV01 for prevention of bronchiolitis obliterans syndrome after respiratory syncytial virus infection in lung transplant recipients. J Heart Lung Transplant 2016;35:213-21.

148.Zamora MR, Budev M, Rolfe M, et al. RNA interference therapy in lung transplant patients infected with respiratory syncytial virus. Am J Respir Crit Care Med 2011;183:531-8.

149. Vos R, Vanaudenaerde BM, Geudens N, et al. Pseudomonal airway colonisation: risk factor for bronchiolitis obliterans syndrome after lung transplantation? Eur Respir J 2008;31:1037-45.

150. Botha P, Archer L, Anderson RL, et al. Pseudomonas aeruginosa colonization of the allograft after lung transplantation and the risk of bronchiolitis obliterans syndrome. Transplantation 2008;85:771-4.

151. Gottlieb J, Mattner F, Weissbrodt H, et al. Impact of graft colonization with gram-negative bacteria after lung transplantation on the development of bronchiolitis obliterans syndrome in recipients with cystic fibrosis. Respir Med 2009;103:743-9.

152. Borthwick LA, Suwara MI, Carnell SC, et al. Pseudomonas aeruginosa Induced Airway Epithelial Injury Drives 
Fibroblast Activation: A Mechanism in Chronic Lung Allograft Dysfunction. Am J Transplant 2016;16:1751-65.

153. Van Delden C, Iglewski BH. Cell-to-cell signaling and Pseudomonas aeruginosa infections. Emerg Infect Dis 1998;4:551-60.

154. Moore CA, Pilewski JM, Venkataramanan R, et al. Effect of aerosolized antipseudomonals on Pseudomonas positivity and bronchiolitis obliterans syndrome after lung transplantation. Transpl Infect Dis 2017;19.

155.Konstan MW, Geller DE, Minić P, et al. Tobramycin inhalation powder for $\mathrm{P}$. aeruginosa infection in cystic fibrosis: the EVOLVE trial. Pediatr Pulmonol 2011;46:230-8.

156. Suhling H, Rademacher J, Greer M, et al. Inhaled colistin following lung transplantation in colonised cystic fibrosis patients. Eur Respir J 2013;42:542-4.

157. Weigt SS, Elashoff RM, Huang C, et al. Aspergillus colonization of the lung allograft is a risk factor for bronchiolitis obliterans syndrome. Am J Transplant 2009;9:1903-11.

158. Weigt SS, Copeland CA, Derhovanessian A, et al. Colonization with small conidia Aspergillus species is associated with bronchiolitis obliterans syndrome: a twocenter validation study. Am J Transplant 2013;13:919-27.

159.Peghin M, Monforte V, Martin-Gomez MT, et al. 10 years of prophylaxis with nebulized liposomal amphotericin $\mathrm{B}$ and the changing epidemiology of Aspergillus spp. infection in lung transplantation. Transpl Int 2016;29:51-62.

160. Borro JM, Solé A, de la Torre M, et al. Efficiency and safety of inhaled amphotericin B lipid complex (Abelcet) in the prophylaxis of invasive fungal infections following lung transplantation. Transplant Proc 2008;40:3090-3.

161. Husain S, Paterson DL, Studer S, et al. Voriconazole prophylaxis in lung transplant recipients. Am J Transplant 2006;6:3008-16.

162. Kolaitis NA, Duffy E, Zhang A, et al. Voriconazole increases the risk for cutaneous squamous cell carcinoma after lung transplantation. Transpl Int 2017;30:41-8.

163. D'Ovidio F, Singer LG, Hadjiliadis D, et al. Prevalence of gastroesophageal reflux in end-stage lung disease candidates for lung transplant. Ann Thorac Surg 2005;80:1254-60.

164. Mohammed A, Neujahr DC. Gastroesophageal reflux disease and graft failure after lung transplantation. Transplant Rev (Orlando) 2010;24:99-103.

165. Hadjiliadis D, Duane Davis R, Steele MP, et al. Gastroesophageal reflux disease in lung transplant recipients. Clin Transplant 2003;17:363-8.
166. Blondeau K, Mertens V, Vanaudenaerde BA, et al. Gastrooesophageal reflux and gastric aspiration in lung transplant patients with or without chronic rejection. Eur Respir J 2008;31:707-13.

167. Palmer SM, Miralles AP, Howell DN, et al.

Gastroesophageal reflux as a reversible cause of allograft dysfunction after lung transplantation. Chest 2000;118:1214-7.

168. Young LR, Hadjiliadis D, Davis RD, et al. Lung transplantation exacerbates gastroesophageal reflux disease. Chest 2003;124:1689-93.

169. Hathorn KE, Chan WW, Lo WK. Role of gastroesophageal reflux disease in lung transplantation. World J Transplant 2017;7:103-16.

170.Mertens V, Blondeau K, Pauwels A, et al. Azithromycin reduces gastroesophageal reflux and aspiration in lung transplant recipients. Dig Dis Sci 2009;54:972-9.

171.Jamie Dy F, Freiberger D, Liu E, et al. Impact of gastroesophageal reflux and delayed gastric emptying on pediatric lung transplant outcomes. J Heart Lung Transplant 2017;36:854-61.

172. Davis RD Jr, Lau CL, Eubanks S, et al. Improved lung allograft function after fundoplication in patients with gastroesophageal reflux disease undergoing lung transplantation. J Thorac Cardiovasc Surg 2003;125:533-42.

173. Cantu E 3rd, Appel JZ 3rd, Hartwig MG, et al. J. Maxwell Chamberlain Memorial Paper. Early fundoplication prevents chronic allograft dysfunction in patients with gastroesophageal reflux disease. Ann Thorac Surg 2004;78:1142-51; discussion 1142-51.

174.Lau CL, Palmer SM, Howell DN, et al. Laparoscopic antireflux surgery in the lung transplant population. Surg Endosc 2002;16:1674-8.

175. Burton PR, Button B, Brown W, et al. Medium-term outcome of fundoplication after lung transplantation. Dis Esophagus 2009;22:642-8.

176. Hartwig MG, Anderson DJ, Onaitis MW, et al. Fundoplication after lung transplantation prevents the allograft dysfunction associated with reflux. Ann Thorac Surg 2011;92:462-8; discussion 468-9.

177. Hoppo T, Jarido V, Pennathur A, et al. Antireflux surgery preserves lung function in patients with gastroesophageal reflux disease and end-stage lung disease before and after lung transplantation. Arch Surg 2011;146:1041-7.

178. Fisichella PM, Davis CS, Lundberg PW, et al. The protective role of laparoscopic antireflux surgery against aspiration of pepsin after lung transplantation. Surgery 
2011;150:598-606.

179. Fisichella PM, Davis CS, Lowery E, et al. Pulmonary immune changes early after laparoscopic antireflux surgery in lung transplant patients with gastroesophageal reflux disease. J Surg Res 2012;177:e65-73.

180. Walter S, Gudowius P, Bosshammer J, et al. Epidemiology of chronic Pseudomonas aeruginosa infections in the airways of lung transplant recipients with cystic fibrosis. Thorax 1997;52:318-21.

181. Roby BB, McNamara J, Finkelstein M, et al. Sinus surgery in cystic fibrosis patients: comparison of sinus and lower airway cultures. Int J Pediatr Otorhinolaryngol 2008;72:1365-9.

182. Nunley DR, Grgurich W, Iacono AT, et al. Allograft colonization and infections with pseudomonas in cystic fibrosis lung transplant recipients. Chest

Cite this article as: Van Herck A, Verleden SE, Vanaudenaerde BM, Verleden GM, Vos R. Prevention of chronic rejection after lung transplantation. J Thorac Dis 2017;9(12):5472-5488. doi: $10.21037 /$ jtd. 2017.11 .85
1998;113:1235-43.

183. Holzmann D, Speich R, Kaufmann T, et al. Effects of sinus surgery in patients with cystic fibrosis after lung transplantation: a 10-year experience. Transplantation 2004;77:134-6.

184. Vital D, Hofer M, Boehler A, et al. Posttransplant sinus surgery in lung transplant recipients with cystic fibrosis: a single institutional experience. Eur Arch Otorhinolaryngol 2013;270:135-9.

185. Vital D, Hofer M, Benden C, et al. Impact of sinus surgery on pseudomonal airway colonization, bronchiolitis obliterans syndrome and survival in cystic fibrosis lung transplant recipients. Respiration 2013;86:25-31.

186.Leung MK, Rachakonda L, Weill D, et al. Effects of sinus surgery on lung transplantation outcomes in cystic fibrosis. Am J Rhinol 2008;22:192-6. 